\title{
Modelagem da dispersão de coliformes termotolerantes e enterococos em duas enseadas na região costeira de Ubatuba (SP), Brasil
}

\author{
Modeling of the dispersion of thermotolerant coliforms and \\ enterococci in two bays in the coastal region of Ubatuba (SP), Brazil
}

\section{Silvana Simone Batista', Joseph Harari²}

$\square$

\begin{abstract}
RESUMO
Foram avaliados os efeitos de ações antrópicas sobre o sistema costeiro de Ubatuba (SP) através de modelos que descrevem os mecanismos e as reações envolvidas na dispersão de indicadores microbiológicos (coliformes termotolerantes e enterococos) na água do mar. A análise da qualidade das águas destinadas à recreação, além de ser uma ação importante em termos de saúde pública, também se justifica em vista da importância da atividade turística em Ubatuba, possuindo, ainda, grande relevância para o planejamento ambiental. Na modelagem, foram utilizados os módulos do sistema Delft3D. No módulo de qualidade da água, foram estudados os mecanismos de dispersão dos poluentes, a partir da associação de dados de poluição com os resultados do módulo hidrodinâmico, em duas enseadas em Ubatuba (SP): Flamengo e Palmas. Os resultados obtidos permitem afirmar que o sistema de correntes nas enseadas, determinado pela geomorfologia da região, não confere alta capacidade de diluição e dispersão de efluentes na área de estudo. Todavia, a circulação marinha e os processos envolvidos no decaimento das bactérias são suficientes para difundir e diminuir suas concentrações ao longo das enseadas. Concluiu-se que a modelagem ambiental reproduziu de maneira satisfatória os processos envolvidos no transporte e na difusão de indicadores microbiológicos, contribuindo com os estudos sobre os efeitos das atividades antrópicas no sistema costeiro de Ubatuba.
\end{abstract}

Palavras-chave: modelagem ambiental; modelagem hidrodinâmica; qualidade da água; indicadores fecais; Litoral Norte de São Paulo.

\begin{abstract}
The effects of human activities on the coastal system of Ubatuba (SP) were evaluated through models that describe the mechanisms and reactions involved in the dispersal of microbiological indicators (thermotolerant coliforms and enterococci) in seawater. Analysis of the quality of water intended for recreation as well as being an important action in terms of public health, is also justified in view of the importance of tourism in Ubatuba, having also great importance to environmental planning. In modeling, the modules Delft3D system were used. In the water quality module, the pollutants dispersal mechanisms were studied, from the association of pollution data with the results of the hydrodynamic module, in two bays in Ubatuba: Flamengo and Palmas. The results allow us to state that the system of currents, determined by the geomorphology of the area, does not provide high capacity for dilution and dispersion of effluents in the study area. However, the marine circulation and the processes involved in the decay of bacteria are enough to spread and reduce their concentrations along the bays. It was concluded that environmental modeling reproduced satisfactorily the processes involved in the transport and diffusion of microbiological indicators, contributing to the studies on the effects of human activities on the coastal system of Ubatuba.
\end{abstract}

Keywords: environmental modeling; hydrodynamic modeling; water quality; fecal indicators; northern coast of São Paulo.

\section{INTRODUÇÃO}

O Litoral Norte de São Paulo caracteriza-se pela diversidade de recursos naturais, pelo elevado potencial turístico e pela intensa especulação imobiliária. O município de Ubatuba está entre os destinos mais visitados de São Paulo, fazendo parte dos 30 destinos turísticos brasileiros mais visitados (SÃO PAULO, 2011). Sua economia é marcada pela sazonalidade decorrente da predominância do turismo veranista, que é o seu principal fator de desenvolvimento (SÃO PAULO, 2005). 口-

'Oceanógrafa pela Universidade de São Paulo (USP). Mestre em Ciência Ambiental pelo Programa de Pós-graduação em Ciência Ambiental (PROCAM) do Instituto de Energia e Ambiente (IEE) da USP - São Paulo (SP), Brasil.

2Professor associado do Departamento de Oceanografia Física, Química e Geológica do Instituto Oceanográfico da Universidade de São Paulo (IO-USP) - São Paulo (SP), Brasil. Endereço para correspondência: Silvana Simone Batista - Rua Izaura Lima Bono, 244 - Parque Vitória Régia - 18078-380 - Sorocaba (SP), Brasil - E-mail: silvana.batista@usp.br Recebido: 15/01/16 - Aceito: 22/07/16 - Reg. ABES: 158594 
A região apresenta elevado potencial de poluição na zona costeira e nos ambientes aquáticos em função de atividades de apoio náutico, tais como iate clubes, marinas, garagens e oficinas de manutenção de embarcações. Dentre os problemas ocasionados por essas atividades, destacam-se: a drenagem de água oleosa do porão das embarcações; o descarte de lixo e resíduos sólidos diretamente no mar; e as embarcações sem estrutura sanitária adequada, que lançam os dejetos diretamente na água (CETESB, 2005).

Em sua maioria, os municípios litorâneos paulistas dispõem de baixa cobertura de rede de coleta de esgoto (42\%) quando comparados à média do estado (89\%), e sistemas de tratamento de esgoto insuficientes (40\%), segundo informações da Fundação Seade. Isto leva a população (residente, flutuante ou do comércio) a construir e operar sistemas de tratamentos inadequados, lançando seus esgotos diretamente em rios e córregos, ou ainda no sistema de drenagem de águas pluviais (CETESB, 2014). Ademais, com o aumento da população durante os períodos de férias e feriados prolongados, os sistemas de esgotamento sanitário existentes não são suficientes para apartar os despejos e, com $o$ advento de chuvas intensas, podem extravasar ou afluir para galerias de águas pluviais, cursos d’água ou praias, o que naturalmente prejudica as condições de balneabilidade (CETESB, 2009).

A avaliação de variáveis microbiológicas tem sido usada como medida de proteção à saúde humana em águas consideradas impactadas pela poluição fecal (JUNG et al., 2014). As fontes de organismos patogênicos e não patogênicos em águas recreacionais marinhas podem ser a presença de esgoto não tratado, lixo, águas de drenagem, urina e fezes de animais (ZHU et al., 2011; McBRIDE et al. 2013). A presença desses patógenos, tanto na areia como na água, consiste em uma ameaça à saúde dos banhistas, que podem estar sujeitos a doenças como gastroenterites, doenças respiratórias, infecções de pele, otite, entre outras (SALIBA; HELMER, 1990; PICKERING et al., 2011).

Os enterococos são recomendados para uso na avaliação do risco das águas recreacionais para a saúde e têm sido correlacionados com efeitos adversos à saúde humana em estudos epidemiológicos (WHO, 2006; BOEHM; SASSOUBRE, 2014; SOLLER et al., 2014). Os coliformes termotolerantes são os microrganismos de primeira escolha para avaliação da poluição de origem fecal no ambiente, uma vez que são constituídos predominantemente pela bactéria Escherichia coli, considerada atualmente o indicador mais adequado (CETESB, 2015).

O presente trabalho tem como objetivo avaliar os efeitos das ações antrópicas sobre o sistema costeiro de Ubatuba-SP com base na modelagem dos processos envolvidos na dispersão de parâmetros microbiológicos (coliformes termotolerantes e enterococos), associados ao lançamento de efluentes domésticos em cursos d'água afluentes às praias e outras fontes não pontuais de esgoto.

Os processos que regem o transporte e a difusão de poluentes em corpos d'água são tão numerosos e complexos que não é possível descrevê-los sem a utilização de modelos matemáticos, que se tornam, portanto, um instrumento técnico indispensável para a gestão ambiental. Os modelos matemáticos e programas computacionais têm sido cada vez mais utilizados como agentes facilitadores no suporte a decisões gerenciais, dentre as alternativas de gestão e uso dos recursos hídricos (MENDONÇA, 2001).

No estudo apresentado neste artigo é usado o modelo Delft3D, desenvolvido pela WL Delft Hydraulics, na Holanda (DELTARES, 2014a). O Delft3D é capaz de simular fluxos não estacionários em 2D ou 3D, fenômenos de transporte resultantes de marés, descarga de água e efeitos meteorológicos, incluindo o efeito de diferenças de densidade devido a gradientes horizontais dos campos de temperatura e salinidade e a vazões fluviais. Desta forma, este modelo pode ser usado em problemas envolvendo diferentes ambientes, como, por exemplo, em mares, regiões costeiras, estuários, reservatórios e rios (LUIJENDIJK, 2001).

O Delft3D é um modelo ambiental aplicado à poluição, sendo muito utilizado na modelagem de dispersão de poluentes nas engenharias química, oceânica e de recursos hídricos (BRUM et al., 2011). Garcia e Gonçalves (2011) utilizaram o Delft3D para avaliar a circulação e o transporte de sedimentos no reservatório de Itaipu (PR); Pereira e Niencheski (2004) implementaram o modelo para avaliar a qualidade da água da Lagoa dos Patos; Jian, Zhongwu e Wenjun (2014) empregaram o modelo para simular processos de floração de algas, e a sedimentação relacionada, no rio Xiangxi, na China; e Ferreira (2015) utilizou o sistema de modelagem ambiental do Delft3D para avaliar a hidrodinâmica e a dispersão de esgoto na região costeira do Guarujá (SP).

Os modelos computacionais são fundamentais em estudos de impacto ambiental, sendo o fator mais importante para apoiar as decisões políticas. Para um modelo se qualificar como uma ferramenta de apoio à decisão, ele deve ser capaz de produzir resultados que descrevam situações de referência, geralmente representando condições padrão, bem como cenários hipotéticos e extremos (NEVES, 2007).

\section{ÁREA DE ESTUDO}

A área de estudo está situada na região de Ubatuba, no setor centro-sul do munícipio, e compreende a Enseada do Flamengo e a Enseada das Palmas na Ilha Anchieta $\left(23^{\circ} 34^{\prime} \mathrm{S}-23^{\circ} 29^{\prime} \mathrm{S}, 45^{\circ} 07^{\prime} \mathrm{W}-45^{\circ} 02^{\prime} \mathrm{W}\right)$. A região faz parte do Litoral Norte de São Paulo, que se situa na parte central da Plataforma Continental Sudeste (PCSE), caracterizada por um litoral bastante recortado, com muitas pontas, enseadas e praias de pequena extensão, devido à proximidade da Serra do Mar em relação ao oceano. A Figura 1 apresenta o mapa e a batimetria da região do Litoral Norte de São Paulo, com a área das enseadas do Flamengo e das Palmas em destaque.

A presença de ilhas na região (como a Ilhabela e a Ilha Anchieta) (Figura 1A) funciona como barreira à ação de ondas provenientes do oceano aberto, resultando, assim, em uma baixa energia hidrodinâmica. 
O padrão de drenagem é bastante incipiente e os processos de troca de água e material sedimentar entre a região costeira e a plataforma adjacente são relativamente pequenos (MAHIQUES, 1995).

A Enseada do Flamengo tem profundidade máxima de $14 \mathrm{~m}$, ocupando uma superfície de aproximadamente $18 \mathrm{~km}^{2}$, com largura média de 2,5 km e abrindo-se diretamente ao mar. É orientada na direção norte-sul, tendo, ao fundo, uma extensa praia a nordeste (Praia da Enseada) e duas pequenas baías: o Saco do Perequê-Mirim, situado ao norte, e o Saco da Ribeira, a noroeste (Figura 1B). A região do Saco da Ribeira é protegida contra a ação das ondas, possui profundidade máxima de $5 \mathrm{~m}$ e permite fácil acesso aos barcos. Desta forma, o Saco da Ribeira abriga um local estratégico de onde partem iates, veleiros, lanchas, as escunas para passeios pela orla e pelas ilhas da região e onde os pescadores embarcam e desembarcam os pescados.

Entre o continente e a Ilha Anchieta ocorre uma feição conhecida como o estreito do Boqueirão $\left(23^{\circ} 31,5^{\prime} \mathrm{S}-45^{\circ} 05^{\prime} \mathrm{W}\right)$, com profundidade máxima de $35 \mathrm{~m}$ e inclinações de $10^{\circ}$, sendo uma das várias depressões costeiras presentes no litoral sudeste brasileiro (MAHIQUES, 1995). A Ilha Anchieta é a segunda maior ilha do Litoral Norte de São Paulo, possuindo uma área de aproximadamente $10 \mathrm{~km}^{2}$ coberta por uma vegetação classificada como área tropical florestada, semelhante à da encosta da Serra do Mar. Por ter sido muito afetada por atividades antropogênicas, como turismo e pesca, a Ilha Anchieta foi declarada, em 1977, reserva ecológica do estado de São Paulo (MANTELATTO et al., 2004).

A Enseada das Palmas é um corpo de água com um volume de $2,5 \times 10^{7}$ $\mathrm{m}^{3}$ e ocupa uma área de $2 \times 10^{6} \mathrm{~m}^{2}$ na face norte da Ilha Anchieta, possuindo profundidade máxima em torno de $10 \mathrm{~m}$. Na Enseada das Palmas há duas praias maiores na porção sul: a Praia das Palmas (ou Praia Grande), com aproximadamente $1000 \mathrm{~m}$ de extensão; e a Praia do Presídio, com $500 \mathrm{~m}$. Na parte leste há duas menores: a Praia do Engenho e a Prainha de Fora, com cerca de 100 m cada (ABSHER, 1982), como mostra a Figura 1C.

\section{METODOLOGIA}

\section{A Modelagem}

\section{O modelo numérico}

O Delft3D é um pacote de modelos para ambientes aquáticos, que possibilita a representação dos sistemas através de módulos (DELTARES, 2014a). No presente trabalho foram utilizados os módulos hidrodinâmico (FLOW) e de qualidade da água (WAQ).

O módulo FLOW consiste em um modelo que resolve as equações hidrodinâmicas do escoamento e do transporte de substâncias para os casos bidimensionais e tridimensionais, utilizando o método de diferenças finitas (DELTARES, 2014b). Este módulo fornece as condições hidrodinâmicas que são utilizadas pelo módulo de qualidade de água (WAQ).

A seguir, são apresentadas as equações do movimento resolvidas pelo módulo FLOW, no plano Ox,y, $\sigma$. A Equação 1 representa o movimento horizontal na direção zonal, e a Equação 2 representa o movimento horizontal na direção meridional. Na Equação 3 (equação da relação hidrostática) está representado o movimento na vertical, e a Equação 4 indica a conservação de massa (equação da continuidade).

$$
\frac{\partial U}{\partial t}+U \frac{\partial U}{\partial x}+V \frac{\partial U}{\partial y}+\frac{W}{H} \frac{\partial U}{\partial \sigma}-f V=-\frac{\nabla P_{x}}{\rho}+\nabla F_{x}+\frac{1}{H^{2}} \frac{\partial}{\partial \sigma}\left(A_{V} \frac{\partial U}{\partial \sigma}\right)+M_{x}
$$

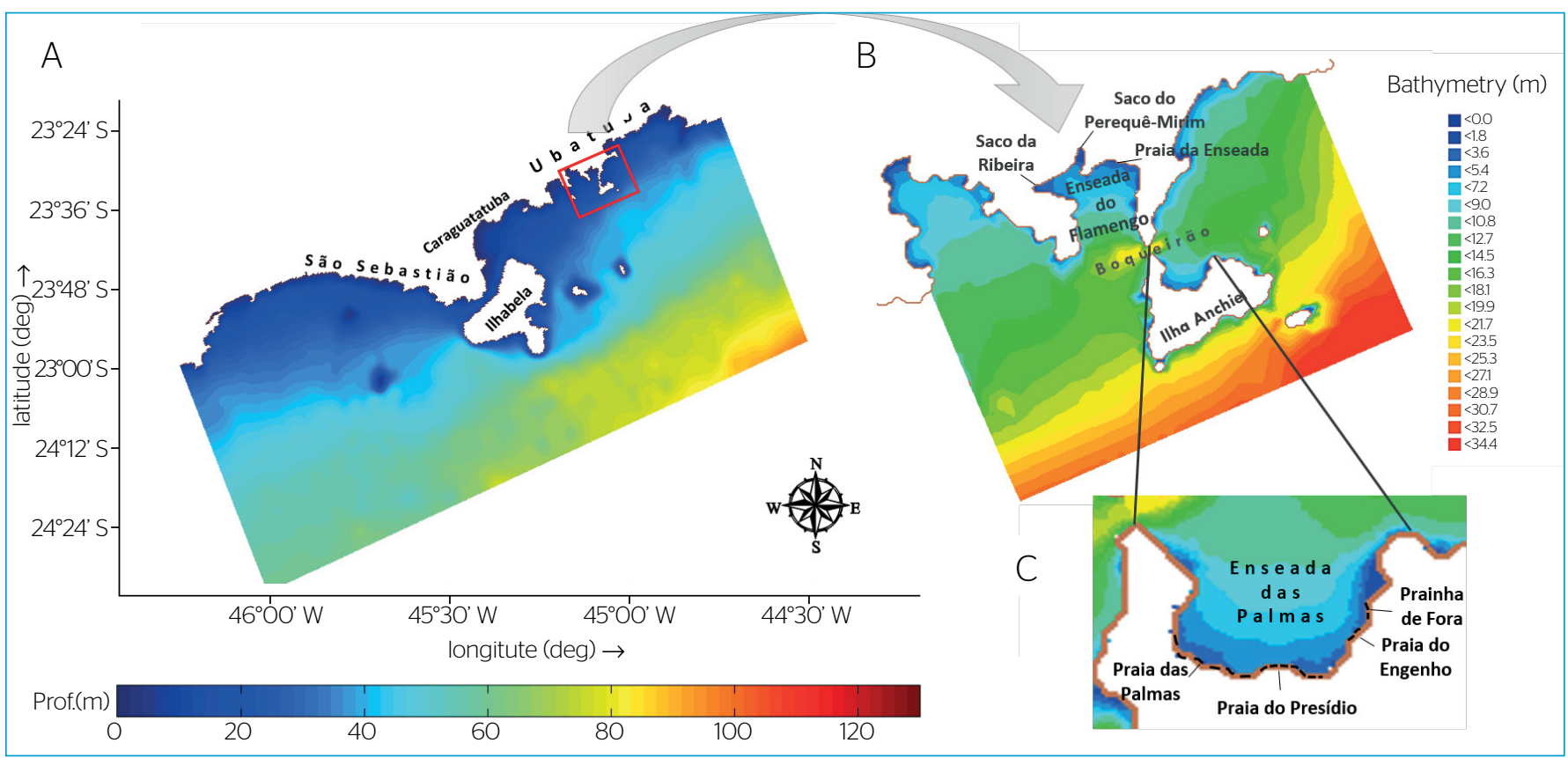

Figura 1 - Mapa e batimetria da região do Litoral Norte de São Paulo, com destaque para a área das Enseadas do Flamengo e das Palmas, em Ubatuba. 
$\frac{\partial V}{\partial t}+U \frac{\partial V}{\partial x}+V \frac{\partial V}{\partial y}+\frac{W}{H} \frac{\partial V}{\partial \sigma}+f U=-\frac{\nabla P_{y}}{\rho}+\nabla F_{y}+\frac{1}{H^{2}} \frac{\partial}{\partial \sigma}\left(A_{V} \frac{\partial V}{\partial \sigma}\right)+M_{y}$

$\frac{\partial P}{\partial \sigma}=-g \rho H$

$\frac{\partial \eta}{\partial t}+\frac{\partial H U}{\partial x}+\frac{\partial H V}{\partial y}-Q=0$

Nas equações, $U$ e $V$ representam as componentes horizontais de velocidade e $W$ a componente vertical. As variáveis $\eta, H, g, \rho, P$, $f$ e $A_{V}$ representam, respectivamente, a elevação do nível do mar, a profundidade média, a aceleração da gravidade, a densidade da água do mar, a pressão hidrostática, o parâmetro de Coriolis e o coeficiente de viscosidade turbulenta vertical. As parcelas contendo $\nabla P_{\mathrm{x}}$ e $\nabla P_{y}$ são os gradientes de pressão hidrostática nas direções $x$ e y; $M_{\mathrm{x}}$ e $M_{\mathrm{y}}$ representam fontes adicionais de movimento segundo x e $\mathrm{y}$; e $Q$ indica fontes de contribuições por unidade de área de descarga de água.

O módulo WAQ é um modelo tridimensional para a representação da qualidade de água de ambientes naturais e artificiais. Este módulo resolve as equações de advecção-difusão-reação para uma grade computacional pré-definida e para uma larga quantidade de substâncias, utilizando o método de elementos finitos. O WAQ tem grande flexibilidade nas substâncias a serem modeladas, assim como nos processos a serem considerados (DELTARES, 2014c).

A Equação 5 corresponde à equação da advecção-difusão-reação resolvida pelo D3D-WAQ. Na equação, $\mathrm{C}$ representa a concentração da substância a ser modelada. As variáveis $K_{\mathrm{H}}$ e $K_{\mathrm{V}}$ são coeficientes de difusão turbulenta na horizontal e na vertical, respectivamente; $\lambda$ é o coeficiente de decaimento; e $F_{\mathrm{R}}$ representa fontes adicionais de reações e outros processos físicos.

$\frac{\partial C}{\partial t}+U \frac{\partial C}{\partial x}+V \frac{\partial C}{\partial y}+\frac{W}{H} \frac{\partial C}{\partial \sigma}=\frac{\partial}{\partial x}\left(K_{H} \frac{\partial C}{\partial x}\right)+\frac{\partial}{\partial y}\left(K_{H} \frac{\partial C}{\partial y}\right)+\frac{1}{H^{2}} \frac{\partial}{\partial \sigma}\left(K_{V} \frac{\partial C}{\partial \sigma}\right)-\lambda C+F_{R}$

As taxas de mortalidade de bactérias coliformes e enterococos podem ser quantificadas com fórmulas empíricas em função da temperatura, clorinidade e radiação solar, demonstradas nas Equações de 6 a 10, a seguir:

Para $T>T_{C i}$ :

$\mathrm{Rmrt}_{i}=k m r t_{i} \times C x_{i}$

$k m r t_{i}=\left(k m b_{i}+k m c l_{i}\right) \times k t m r t_{i}^{T-20}+k m r d$

$\mathrm{kmcl}_{i}=k \mathrm{kl}_{i} \times \mathrm{Ccl}$ $k m r d=k r d \times D L \times f u v \times I 0 \times \frac{\left(1-e^{-\varepsilon \times H}\right)}{\varepsilon \times H}$

$\operatorname{Para} T \leq T_{C i}$ :

$\mathrm{Rmrt}_{i}=0$

Onde, $i=$ índice para o tipo de bactéria (coliformes termotolerantes ou enterococos), $C x_{i}=$ concentração de bactérias, $D L=$ duração do dia (d), $\varepsilon=$ extinção devido a radiação- $U V\left(\mathrm{~m}^{-1}\right), f u v=$ fração da radiação-UV como derivada da luz visível (-), $H=$ profundidade da água (m), $I 0=$ radiação solar incidente na superfície da água $\left(\mathrm{W} \cdot \mathrm{m}^{-2}\right), k c l=$ constante de mortalidade relacionada com cloreto $\left(\mathrm{m}^{3} \cdot \mathrm{g}^{-1} \cdot \mathrm{d}^{-1}\right), k m b=$ taxa básica de mortalidade $\left(\mathrm{d}^{-1}\right), k m c l=$ taxa de mortalidade devido à clorinidade $\left(\mathrm{d}^{-1}\right), k m r d=$ taxa de mortalidade devido à radiação $\left(\mathrm{d}^{-1}\right)$, $k m r t=$ taxa de mortalidade de primeira ordem $\left(\mathrm{d}^{-1}\right), k r d=$ constante da mortalidade relacionada à radiação $\left(\mathrm{m}^{2} . \mathrm{W}^{-1} \cdot \mathrm{d}^{-1}\right), k t m r t=$ coeficiente de temperatura da taxa de mortalidade (-), Rmrt=taxa de mortalidade da bactéria $\left(\mathrm{NMP} \cdot \mathrm{m}^{-3} \cdot \mathrm{d}^{-1}\right), T=$ temperatura $\left({ }^{\circ} \mathrm{C}\right), T c=$ temperatura crítica para mortalidade $\left({ }^{\circ} \mathrm{C}\right)$ e $\mathrm{Ccl}=$ concentração de cloreto $\left(\mathrm{g} \cdot \mathrm{m}^{-3}\right)$.

\section{Preparação do modelo hidrodinâmico}

Foi elaborada uma grade computacional regular de $491 \times 218$ pontos, em coordenadas esféricas, com espaçamento de aproximadamente $350 \mathrm{~m}$, cobrindo todo o Litoral Norte de São Paulo, entre as longitudes de $46^{\circ} 15^{\prime} \mathrm{W}$ a $44^{\circ} 45^{\prime} \mathrm{W}$, e as latitudes de $24^{\circ} 00^{\prime} \mathrm{S}$ a $23^{\circ} 22^{\prime} \mathrm{S}$. A batimetria da região foi obtida por digitalização de cartas náuticas da Diretoria de Hidrografia e Navegação do Brasil (DHN) (ver Figura 1).

O módulo hidrodinâmico foi implementado inicialmente, a fim de determinar a hidrodinâmica em função das forçantes atuantes no sistema (marés, ventos e gradientes de densidade). Como condição inicial, a altura do nível do mar foi considerada nula em todo o domínio, uma vez que o modelo necessita de um tempo de estabilização relativamente curto. A temperatura e a salinidade iniciais foram $20^{\circ} \mathrm{C}$ e 31 ups, respectivamente.

As constantes harmônicas de maré das componentes de maré nos contornos abertos da grade foram obtidas do banco de dados do modelo TPXO (Osu Topex/Poseidon Global Inverse Solution). Os valores de nível médio do mar nos contornos da grade foram especificados a partir de dados de modelagem operacional da plataforma fornecidos pelo Laboratório de Meteorologia Aplicada a Sistemas de Tempo Regionais (MASTER) (disponível em: <http://www.master.iag.usp.br>) (CAMARGO; HARARI, 2014).

O efeito dos ventos na circulação foi introduzido a partir de séries temporais de ventos obtidas do banco de dados do National Center for Environmental Prediction for Atmospheric Research (NCEP/NCAR). Para incluir o efeito do gradiente de densidade nas simulações foram 
utilizados campos tridimensionais horários de temperatura e salinidade nos contornos abertos, a partir de resultados do modelo de plataforma do MASTER.

\section{Preparação do modelo de qualidade da água}

Os resultados obtidos pelo modelo hidrodinâmico foram usados como dados de entrada na implementação do modelo de qualidade da água. $\mathrm{Na}$ interface do WAQ foram montados os cenários, definindo-se as condições iniciais, condições de contorno, tempo de simulação, descarga de resíduos, variáveis de saída, pontos de monitoramento, etc.

Para estudar os impactos do aumento do lançamento de efluentes decorrentes da atividade de turismo, principalmente em épocas de alta temporada, na Enseada do Flamengo e na Enseada das Palmas, foram utilizados dados de coliformes termotolerantes e enterococos obtidos pela Companhia Ambiental do Estado de São Paulo (CETESB) e publicados no Relatório de Qualidade das Praias Litorâneas no Estado de São Paulo (CETESB, 2009).

No Saco da Ribeira, na Enseada do Flamengo, predomina uma ocupação descontínua por população flutuante e se constitui o centro do turismo náutico de Ubatuba. A Tabela 1 indica as concentrações de coliformes termotolerantes obtidas em duas campanhas da CETESB em dois canais afluentes no Saco da Ribeira, em 2009. Por serem canais muito próximos um ao outro, optou-se por utilizar a soma das concentrações em um único ponto de despejo na grade computacional do modelo. As concentrações de coliformes termotolerantes são expressas em "Número Mais Provável" (NMP), por $100 \mathrm{~mL}$ de amostra de água. A concentração de despejo de coliformes utilizada para o período de verão foi de $5,7 \times 10^{4} \mathrm{NMP}$ por $100 \mathrm{~mL}$. Para o período de inverno, utilizou-se o valor de $1,24 \times 10^{3} \mathrm{NMP}$ por $100 \mathrm{~mL}$.

As amostragens nas praias da Ilha Anchieta foram iniciadas em fevereiro de 2006 por técnicos da CETESB, por solicitação da diretoria do Parque Estadual da Ilha Anchieta, em função do afluxo de turistas para visitação. As densidades de enterococos utilizadas no modelo foram obtidas em amostras de água das praias, onde existe a presença de afluentes. O sistema hídrico da Ilha Anchieta é constituído por rios perenes e canais temporários. Na Enseada das Palmas deságuam três cursos d'água perenes, os quais se localizam nos extremos oeste da Praia das Palmas e leste da Praia do Presídio, e entre a Praia do Engenho e a

Tabela 1 - Concentrações de coliformes termotolerantes (NMP por $100 \mathrm{~mL}$ ) obtidos pela CETESB nas duas amostragens efetuadas em 2009 em corpos d'água afluentes no Saco da Ribeira.

\begin{tabular}{l|c|c} 
Afluentes no Saco da Ribeira & Amostragem 1 & Amostragem 2 \\
$\begin{array}{l}\text { Canal afluente ao lado do Ubatuba } \\
\text { late Clube - Ponte }\end{array}$ & 24.000 & 760 \\
\hline $\begin{array}{l}\text { Canal ao lado direito do pier do late } \\
\text { Clube }\end{array}$ & 33.000 & 480 \\
\hline Total & 57.000 & 1.240 \\
\hline
\end{tabular}

Prainha de Fora, e ainda alguns intermitentes que dependem da pluviosidade local (ABSHER, 1982).

Para a análise da balneabilidade das praias, consideram-se representativos, para amostragens, locais em que já tenha ocorrido a mistura das águas do mar com aquelas provenientes de corpos d'água potencialmente poluídos. A amostragem de água da praia é feita preferencialmente na maré vazante, na qual, em princípio, observa-se maior contribuição e menor diluição dos efluentes (CETESB, 2009).

Foram realizadas amostragens mensais nas praias da Enseada da Palmas pela CETESB ao longo do ano de 2009. Para fins de comparação entre alta e baixa temporadas (períodos de verão e inverno), foram utilizados os valores obtidos nos meses de fevereiro e agosto. As concentrações de enterococos são expressas em número de "Unidades Formadoras de Colônias" (UFC) por $100 \mathrm{~mL}$ de amostra de água. Na Tabela 2 são expressas as concentrações de enterococos (em UFC por $100 \mathrm{~mL}$ ) na Praia das Palmas, na Praia do Presídio e na Praia do Engenho.

Na modelagem da dispersão, para a Enseada do Flamengo foram implementados 2 cenários (fevereiro/verão e agosto/inverno), com os dados de densidade de coliformes termotolerantes, e na Enseada das Palmas foram implementados 2 cenários com dados de enterococos (idem). Para monitoramento e análise dos resultados foram selecionados 15 pontos distribuídos na Enseada do Flamengo (FL01 a FL15) e 14 pontos na Enseada das Palmas (PA01 a PA14) (Figura 2).

\section{Validação e análises estatísticas}

Segundo Cheng, Burau e Gartner (1991), um modelo numérico deve ser validado através da comparação dos seus resultados com observações ou resultados de outros modelos, para que possa ser usado como ferramenta de pesquisa de processos hidrodinâmicos. O processo de validação dos resultados hidrodinâmicos seguiu o método proposto por Willmott (1981), que se baseia na análise do parâmetro S (Skill), calculado por meio da Equação 11:

$S=1-\frac{\sum\left(\left|X_{m o d}-X_{o b s}\right|\right)^{2}}{\sum\left(\left|X_{m o d}-\bar{X}_{o b s}\right|+\left|X_{o b s}-\bar{X}_{o b s}\right|\right)^{2}}$

Tabela 2 - Concentrações de enterococos (UFC por $100 \mathrm{~mL}$ ) obtidas pela CETESB, nos meses de fevereiro e agosto de 2009, nas praias da Enseada das Palmas, Ilha Anchieta.

\begin{tabular}{l|c|c|c|c|c|c|c|c} 
& \multicolumn{4}{|c|}{ Fevereiro } & \multicolumn{5}{c}{ Agosto } \\
\hline Local/dia & 1 & 8 & 15 & 22 & 9 & 16 & 23 & 30 \\
\hline $\begin{array}{l}\text { Praia das } \\
\text { Palmas }\end{array}$ & 1 & 88 & 68 & 1 & 3 & 1 & 3 & 5 \\
\hline $\begin{array}{l}\text { Praia do } \\
\text { Presídio }\end{array}$ & 1 & 92 & 92 & 5 & 1 & 1 & 6 & 5 \\
\hline $\begin{array}{l}\text { Praia do } \\
\text { Engenho }\end{array}$ & 1 & 59 & 120 & 4 & 1 & 1 & 42 & 2 \\
\hline
\end{tabular}


Onde $X_{\text {mod }}$ é a série temporal de uma variável calculada pelo modelo, $X_{o b s}$ é a série temporal da variável observada e $\bar{X}_{o b s}$ indica a média das observações no período. O parâmetro $S$ varia entre 0 , representando total discordância entre os dados modelados e observados, e 1, representando perfeita concordância.

A taxa de decaimento (mortalidade) das bactérias coliformes e enterococos é altamente influenciada pela radiação solar, temperatura e salinidade (MANCINI, 1978). Para verificar o grau de correlação entre os parâmetros físicos e as taxas de mortalidade das bactérias foi utilizado o índice de correlação linear de Pearson ( $r$ ), que é calculado pela Equação 12:

$$
r=\frac{\sum_{i=1}^{N}\left(X_{i}-\bar{X}\right)-\left(Y_{i}-\bar{Y}\right)}{\sqrt{\left[\sum_{i=1}^{N}\left(X_{i}-\bar{X}\right)^{2}\right]\left[\sum_{i=1}^{N}\left(Y_{i}-\bar{Y}\right)^{2}\right]}}
$$

Onde $r$ é o coeficiente de correlação linear, $N$ é o número de observações, $X$ é a variável independente (e.g., T ou S) e $Y$ é variável dependente (e.g., taxa de mortalidade). O valor do coeficiente de correlação $r$ tem variação entre +1 e -1 . Se $r=+1$, a correlação é perfeita positiva; se $r=-1$, a correlação é perfeita negativa; e se $r=0$, não há correlação entre as variáveis ou, ainda, a correlação não é linear, caso exista.

\section{RESULTADOS E DISCUSSÃO}

\section{Validação dos Resultados Hidrodinâmicos}

A verificação das condições hidrodinâmicas na área de estudo é o primeiro passo para estudar os processos envolvidos na dispersão

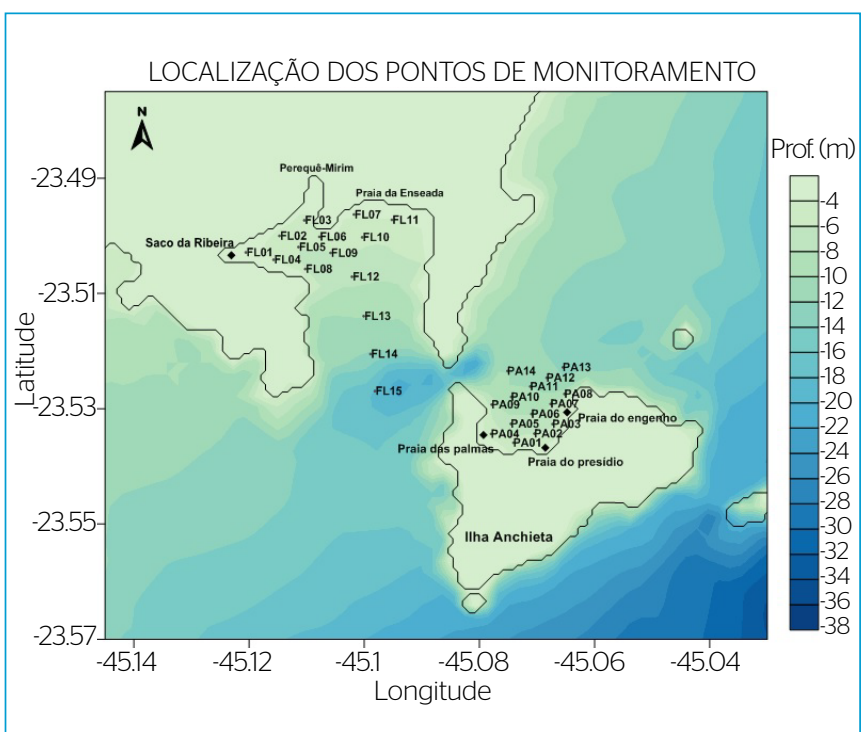

Figura 2- Localização, na área de estudo, dos pontos de monitoramento dos resultados de qualidade da água e localização dos pontos de lançamento de poluentes no Saco da Ribeira e nas praias da Enseada das Palmas ( $\diamond$ ). de poluentes. A fim de validar os resultados da modelagem hidrodinâmica, os dados de saída do modelo foram comparados: com dados de elevação do nível do mar obtidos por previsão harmônica de maré com nove componentes (Q1, O1, P1, K1, N2, M2, S2, K2 e M3); e com dados observados, medidos pelo marégrafo a radar Kalesto, situado na Base de Pesquisa Clarimundo de Jesus do Instituto Oceanográfico da USP (IOUSP) localizado no Saco da Ribeira.

Nas figuras a seguir foram plotadas as séries temporais em agosto de 2009 para comparação dos resultados de elevação do modelo (processado somente com a forçante de maré) com os resultados de previsão harmônica de maré (Figura 3), e para comparação dos resultados de elevação do modelo (processado com todas as forçantes - de maré, vento e densidade) com os dados medidos pelo marégrafo (Figura 4).

Os valores obtidos para o parâmetro $S$ (Equação 11) foram de: 0,997 para a validação dos resultados de maré, indicando concordância quase perfeita entre os resultados do modelo e os dados da previsão harmônica de maré; e 0,935 para a validação dos resultados de elevação do nível do mar considerando todas as forçantes (maré, ventos e densidade).

Pela análise das séries temporais e dos valores dos parâmetros $S$ obtidos, pode-se notar a grande correspondência entre resultados do modelo e previsões de maré ou observações, o que permite afirmar que os resultados do modelo são válidos com um alto grau de confiança e representam bem a hidrodinâmica na região estudo. Desta forma, espera-se que esses resultados reproduzam de forma satisfatória os processos envolvidos na dispersão de poluentes.

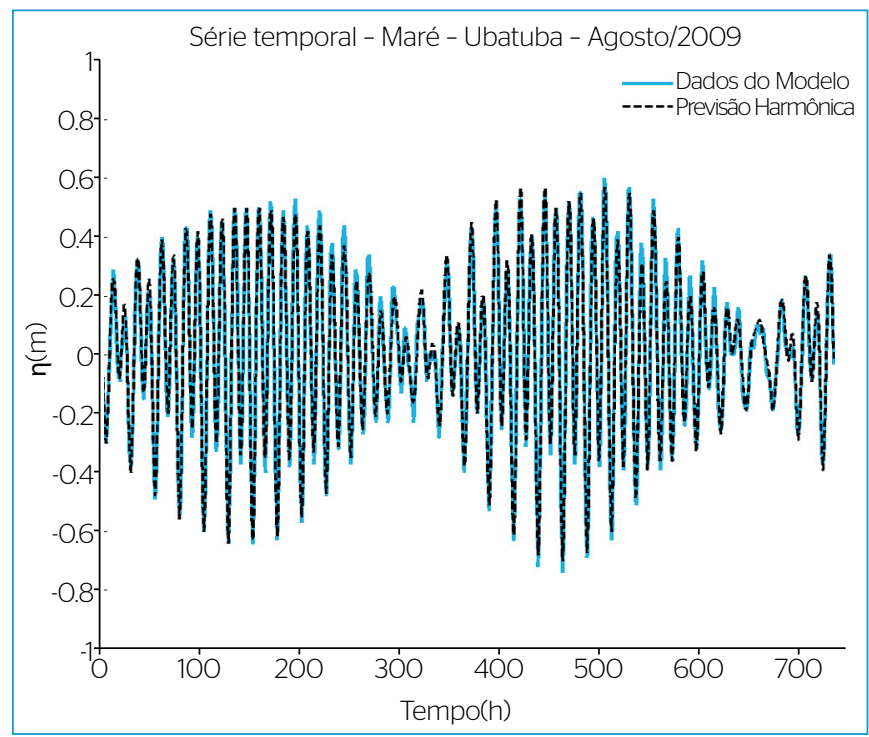

Figura 3 - Séries temporais de maré (m) no mês de agosto de 2009, no Saco da Ribeira em Ubatuba, com dados gerados pelo modelo (linha contínua) e dados da previsão harmônica de maré (linha tracejada). 


\section{Dispersão de Coliformes Termotolerantes na Enseada do Flamengo}

Utilizando os dados da CETESB, o modelo calculou as densidades dos microrganismos nos pontos de monitoramento, na camada de superfície, para os meses de fevereiro e agosto de 2009. As densidades médias e máximas de coliformes termotolerantes na Enseada do Flamengo, para cada ponto de monitoramento, estão indicadas na Tabela 3 .

A maior concentração média de coliformes obtida durante o mês de fevereiro foi no ponto FL01, com cerca de $1000 \mathrm{NMP} / 100 \mathrm{~mL}$ de água. Os pontos FL01, FL02 e FL04 apresentaram as maiores concentrações médias por serem os pontos mais próximos do local de despejo no Saco da Ribeira. Os pontos mais afastados (FL03, FL05 a FL15) apresentaram médias próximas a zero.

Os resultados da simulação para agosto mostram concentrações médias muito baixas de coliformes. Os pontos com maior quantidade de coliformes por mililitro, FL01 e FL04, atingiram média mensal de 25,75 $\mathrm{NMP} / 100 \mathrm{~mL}$ e 17,43 NMP/100 mL, respectivamente. O ponto FL01 apresentou uma concentração máxima de coliformes de 1850,73 NMP/100 $\mathrm{mL}$ de amostra, e o ponto FL04 atingiu máxima de 1300,87 NMP/100 mL.

Muitos fatores influenciam as concentrações de coliformes na água do mar, onde os indicadores fecais podem sofrer decaimento pelos raios solares e estão expostos à ação de bacteriófagos, baixa quantidade de nutrientes, predação e competição com organismos autóctones. As densidades bacterianas também diminuem com o aumento da salinidade da água, devido ao aumento da pressão osmótica decorrente do aumento da salinidade (BELKIN; COLWELL, 2006).

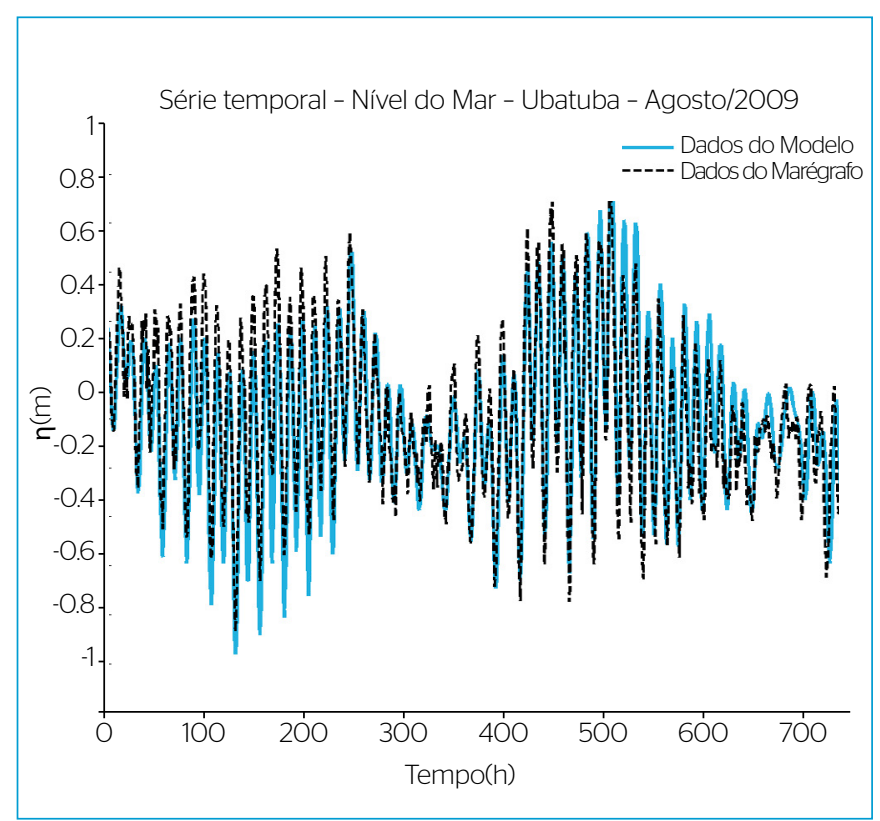

Figura 4 - Séries temporais da elevação do nível do $\operatorname{mar}(m)$ do mês de agosto de 2009, no Saco da Ribeira em Ubatuba, com dados gerados pelo modelo (linha contínua) e dados medidos pelo marégrafo do IOUSP (linha tracejada).
Para analisar melhor essas relações, foram feitas análises de correlação de Pearson entre as taxas de mortalidade geral de coliformes, a salinidade e a temperatura. $O$ índice de correlação linear (r) obtido entre a mortalidade geral e a temperatura foi $r=0,99$; e entre a mortalidade e a salinidade foi $r=0,94$. Esses valores indicam alta correlação positiva entre os parâmetros, ou seja, a taxa de mortalidade de coliformes termotolerantes aumentou com o aumento da temperatura e da salinidade.

Observou-se que as taxas de mortalidade são praticamente constantes ao longo do mês, mas oscilam durante o dia. O mês de fevereiro apresentou taxas de mortalidade maiores do que o mês de agosto. Em fevereiro, a média da mortalidade devido à radiação foi $1,5 \mathrm{~d}^{-1}$, já a mortalidade geral ficou em torno de 2,5 $\mathrm{d}^{-1}$. Em agosto, a média da mortalidade devido à radiação foi $1,1 \mathrm{~d}^{-1}$, e a taxa de mortalidade geral média foi $2,0 \mathrm{~d}^{-1}$. No inverno a quantidade de bactérias coliformes pode sofrer menor decaimento devido à menor incidência de radiação solar na superfície da água.

A partir desses resultados é possível inferir que o efeito da radiação solar contribui com mais da metade da taxa de mortalidade geral, a qual considera o efeito somado da salinidade, da temperatura e da radiação sobre o decaimento das bactérias. De acordo com Mancini (1978), a variação de radiação solar durante o dia pode ter um impacto significativo sobre os padrões de concentração dessas bactérias. O efeito letal da radiação está associado com comprimentos de onda curtos, em particular radiação ultravioleta. Cerca de metade do efeito letal é devido à luz de comprimento de onda abaixo de $370 \mathrm{~nm}$. Comprimentos de onda acima de $500 \mathrm{~nm}$ são ineficazes.

Tabela 3- Resultados de concentrações de coliformes termotolerantes (em NMP por $100 \mathrm{~mL}$ ) nos pontos de monitoramento na Enseada do Flamengo.

\begin{tabular}{l|c|c|c|c}
\multirow{2}{*}{ Ponto } & \multicolumn{2}{|c|}{ Fevereiro/2009 } & \multicolumn{2}{c}{ Agosto/2009 } \\
\cline { 2 - 5 } FL01 & Média & Máximo & Média & Máximo \\
\hline FL02 & 479,17 & 949,52 & 9,60 & 23,20 \\
\hline FL03 & 40,32 & 293,24 & 1,11 & 9,20 \\
\hline FL04 & 466,11 & 1300,87 & 17,43 & 35,54 \\
\hline FL05 & 63,71 & 209,67 & 2,04 & 6,89 \\
\hline FL06 & 7,31 & 102,79 & 0,30 & 3,32 \\
\hline FL07 & 1,42 & 28,61 & 0,13 & 2,54 \\
\hline FL08 & 54,14 & 197,22 & 3,19 & 9,25 \\
\hline FL09 & 12,52 & 76,14 & 0,42 & 2,18 \\
\hline FL10 & 2,05 & 31,59 & 0,10 & 0,95 \\
\hline FL11 & 0,45 & 5,75 & 0,07 & 1,12 \\
\hline FL12 & 1,75 & 9,85 & 0,15 & 0,50 \\
\hline FL13 & 0,46 & 3,69 & 0,05 & 0,31 \\
\hline FL14 & 0,09 & 0,76 & 0,02 & 0,07 \\
\hline FL15 & 0,03 & 0,38 & 0,00 & 0,03 \\
\hline
\end{tabular}


Os resultados da modelagem hidrodinâmica indicaram valores baixos de correntes no Saco da Ribeira ao longo dos meses de simulação, apresentando média de $0,03 \mathrm{~m} \cdot \mathrm{s}^{-1}$, o que pode ser explicado por suas características de semiconfinamento, as quais conferem ao local baixa energia hidrodinâmica. Correntes um pouco mais intensas foram observadas no período de inverno, o que pode ser relacionado à maior ocorrência de sistemas frontais.

Segundo Lançone, Duleba e Mahiques (2005), a Enseada do Flamengo é um ambiente de moderada energia hidrodinâmica, que diminui gradualmente em direção ao continente, desde a desembocadura. As áreas mais internas da enseada caracterizam subambientes com baixa energia deposicional e circulação restrita. De acordo com Mahiques (1992), os valores médios de corrente na Enseada do Flamengo são inferiores a $0,1 \mathrm{~m} \cdot \mathrm{s}^{-1}$.

A circulação na Enseada do Flamengo ocorre devido a uma corrente que penetra em direção norte, bifurcando-se em dois ramos: um na direção NNE de baixa penetração e outro na direção NNO. Segundo Mahiques, Tessler e Furtado (1998), a Enseada do Flamengo sofre a influência de ondas de sudeste, sul e leste, sendo que as de sul e sudeste são as mais fortes, pois apresentam menor grau de difração.

$\mathrm{Na}$ Figura 5 está ilustrada a dispersão de coliformes termotolerantes, o campo de concentrações em NMP.m ${ }^{-3}$ e a direção das correntes atuantes numa situação de maré enchente em sizígia, às 3:00h (GMT) do dia 25/02/2009. Observa-se que na maré enchente a pluma do poluente é transportada para a região mais ao norte da enseada. Devido ao fato das correntes serem fracas, há pouca dispersão do poluente e maior concentração deste na pequena baía do Saco da Ribeira.

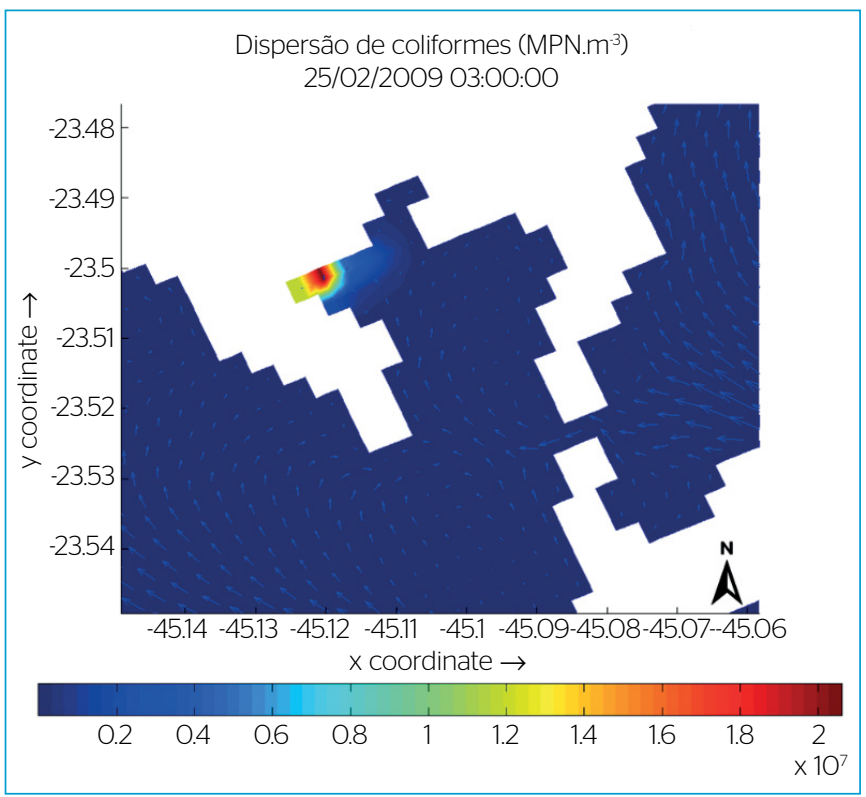

Figura 5 - Dispersão de coliformes termotolerantes e direção das correntes em situação de maré de sizígia, na enchente, na região da Enseada do Flamengo, às 3:00h (GMT) do dia 25/02/2009.
Na Figura 6 pode ser visualizado o campo de velocidade das correntes na enseada no mesmo instante referente à Figura 5. Nota-se que a magnitude das correntes no interior da Enseada do Flamengo é em torno de $0,03 \mathrm{~m} \cdot \mathrm{s}^{-1}$.

Castro (1996), através de estudos observacionais ao largo de Ubatuba (SP), verificou na plataforma interna, durante o inverno, fluxo predominante para sudoeste em três anos consecutivos, havendo eventos de inversão para nordeste (nas entradas de sistemas frontais). A dispersão de coliformes associada às correntes mais fortes na direção NE, associadas a ventos de SE, durante a passagem de um sistema frontal, às 19:00h do dia 21/08/2009, pode ser visualizada na Figura 7.

Os resultados indicam o transporte de poluentes em direção às regiões internas ao norte e nordeste da enseada (praias do PerequêMirim e da Enseada) devido à configuração e velocidade das correntes. O campo de velocidades pode ser visualizado na Figura 8. As correntes na enseada são de cerca $0,1 \mathrm{~m} \cdot \mathrm{s}^{-1}$, atingindo $0,6 \mathrm{~m} \cdot \mathrm{s}^{-1}$ no estreito do Boqueirão.

\section{Dispersão de Enterococos na Enseada das Palmas}

$\mathrm{Na}$ Tabela 4 se encontram os resultados das densidades médias e máximas de enterococos nos pontos de monitoramento na Enseada das Palmas. A maior densidade média de enterococos durante o mês de fevereiro de 2009 foi obtida no ponto PA03 (0,38 UFC/100 mL) próximo à Praia do Engenho. Os pontos localizados mais próximos às praias (Praia das Palmas, Praia do Presídio e Praia do Engenho), PA01 a PA04, apresentaram concentrações médias maiores do que os pontos

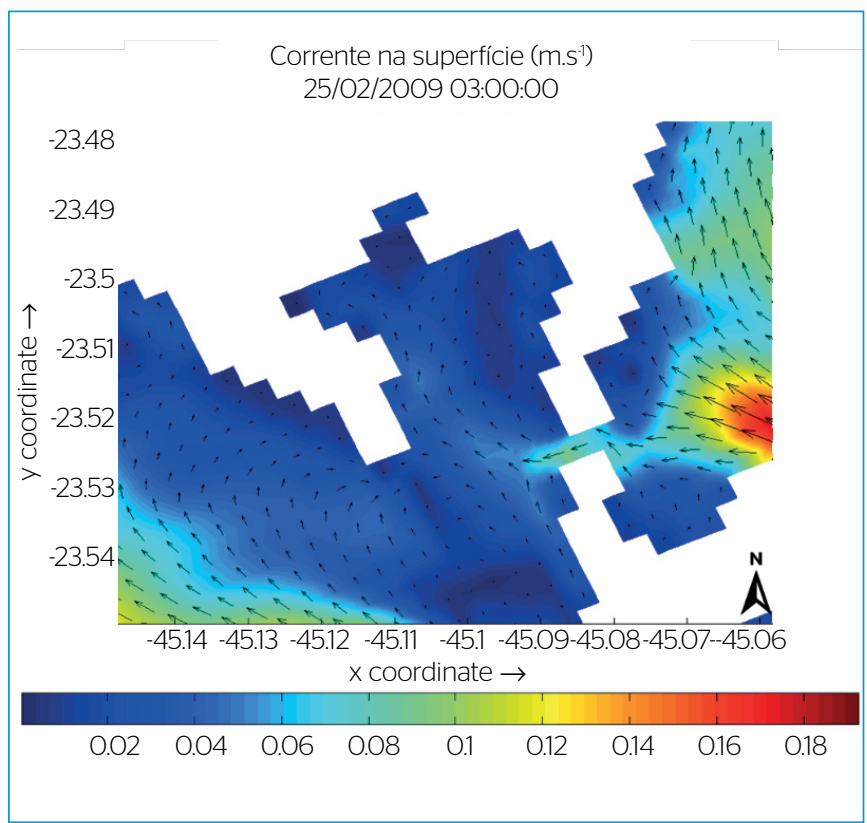

Figura 6 - Direção e intensidade das correntes (em m.s. ${ }^{-1}$ ) na região da Enseada do Flamengo, às 3:00h (GMT) do dia 25/02/2009. 
mais afastados (PA05 a P014). No mês de agosto de 2009 o maior valor médio foi de aproximadamente 0,07 UFC/100 mL.

No geral, tanto em fevereiro quanto em agosto as densidades médias de enterococos obtidas na superfície foram muito baixas, sendo até mesmo nulas em alguns pontos. Em fevereiro o valor máximo obtido foi de 1,21 UFC/100 mL no ponto PA02, próximo à Praia do Presídio. Em agosto, o pico máximo de enterococos foi de $0,36 \mathrm{UFC} / 100 \mathrm{~mL}$ no ponto PA03.

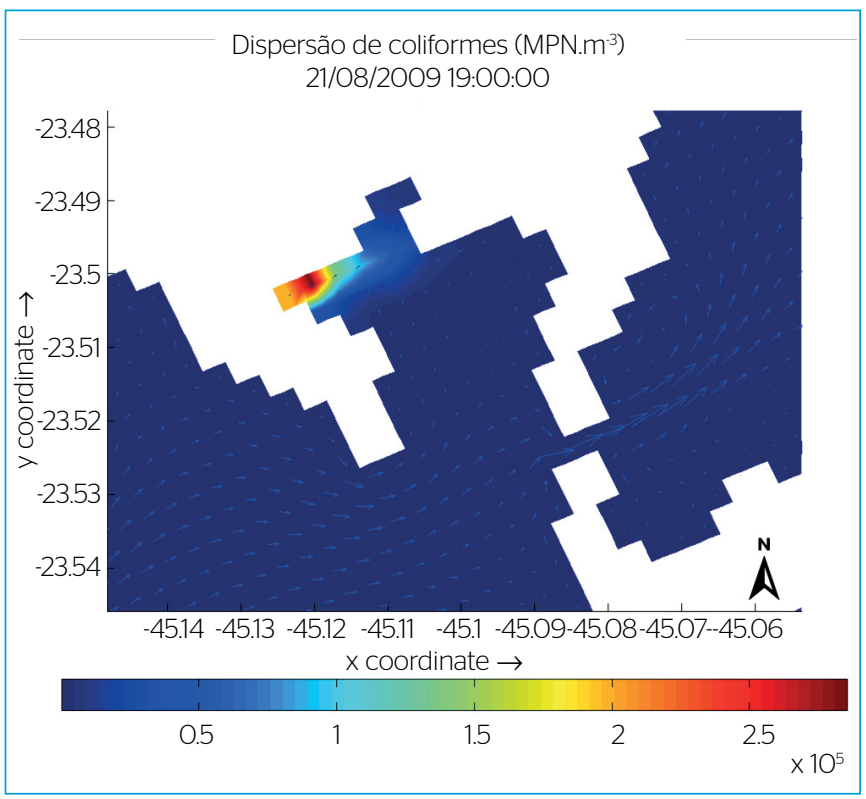

Figura 7 - Dispersão de coliformes termotolerantes e direção das correntes na região da Enseada do Flamengo, às 19:00h (GMT) do dia 21/08/2009, durante a passagem de um sistema frontal.

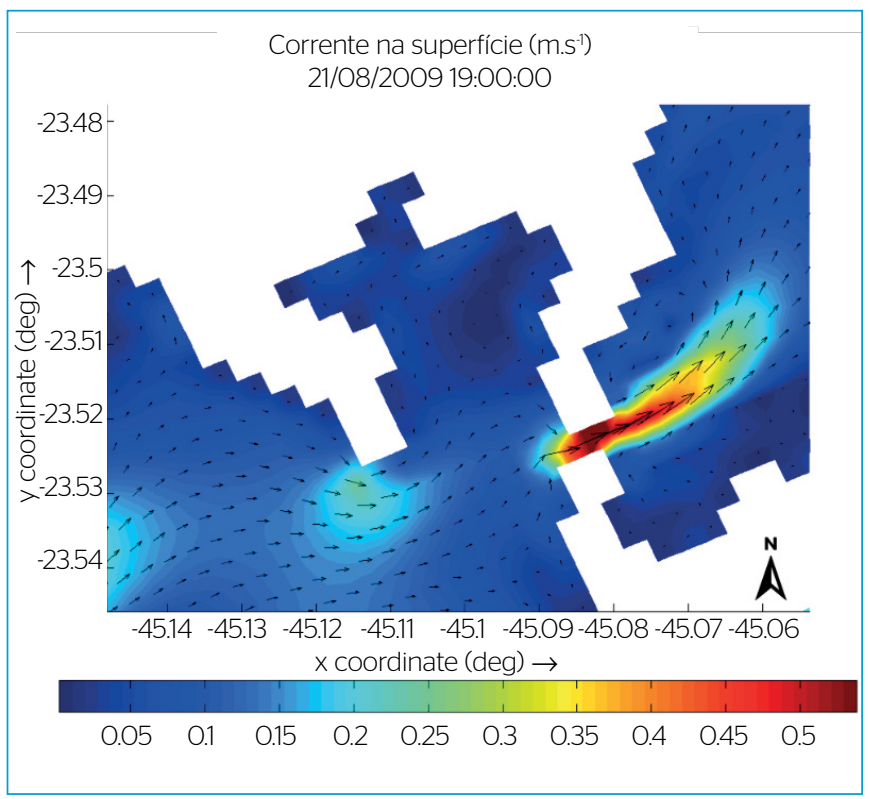

Figura 8 - Direção e intensidade das correntes (em m.s. Enseada do Flamengo, às 19:00h (GMT) do dia 21/08/2009, durante a passagem de um sistema frontal.
Foram analisados os índices de correlação de Pearson, para avaliar a correlação entre a taxa de mortalidade geral de enterococos e os valores de salinidade e de temperatura. Foi obtido índice $r=0,75$ entre a taxa de mortalidade geral e a temperatura, indicando forte correlação positiva entre esses dois parâmetros. Ou seja, a taxa de decaimento de enterococos aumenta em função do aumento da temperatura. Entre a taxa de mortalidade e a salinidade obteve-se uma correlação muito fraca, com índice $r=-0,02$, impossibilitando estabelecer uma relação entre as variáveis.

Em fevereiro, as taxas de mortalidade geral e de mortalidade em função da radiação solar apresentaram valores médios em torno de $2,3 \mathrm{~d}^{-1}$ e $1,2 \mathrm{~d}^{-1}$, respectivamente. Em agosto a taxa de mortalidade geral foi $1,8 \mathrm{~d}^{-1}$, e a mortalidade devido à radiação solar, $0,9 \mathrm{~d}^{-1}$. Esses valores indicam a forte influência da radiação solar no decaimento de enterococos.

A Figura 9 mostra uma situação em que a circulação, com correntes de nordeste, dispersa os poluentes, forçando-os para fora da enseada, passando pelo estreito do Boqueirão e fluindo para sudoeste, às 13:00h (GMT) do dia 30/08/09. Percebe-se que a pluma de poluentes atinge a entrada da Enseada do Flamengo e segue em direção à costa, com concentração de enterococos em torno de 100 UFC. $\mathrm{m}^{-3}$. A maior concentração de enterococos permanece na Enseada das Palmas, atingindo o máximo de 600 UFC. $\mathrm{m}^{-3}$ próximo à Praia das Palmas.

Na Figura 10, pode-se observar a direção e a magnitude das correntes que influenciam o transporte de enterococos, às 13:00h (GMT) do dia 30/08/2009. Na passagem do Boqueirão as correntes têm velocidade

Tabela 4 - Resultados de concentrações de enterococos (em UFC por $100 \mathrm{~mL}$ ) nos pontos de monitoramento na Enseada das Palmas.

\begin{tabular}{l|c|c|c|c}
\multirow{2}{*}{ Ponto } & \multicolumn{2}{|c|}{ Fevereiro/2009 } & \multicolumn{2}{c}{ Agosto/2009 } \\
\cline { 2 - 5 } & Média & Máximo & Média & Máximo \\
\hline PA02 & 0,22 & 0,57 & 0,03 & 0,14 \\
\hline PA03 & 0,29 & 1,21 & 0,04 & 0,20 \\
\hline PA04 & 0,38 & 1,09 & 0,07 & 0,36 \\
\hline PA05 & 0,10 & 0,86 & 0,02 & 0,09 \\
\hline PA06 & 0,10 & 0,68 & 0,01 & 0,08 \\
\hline PA07 & 0,16 & 0,92 & 0,01 & 0,11 \\
\hline PA08 & 0,04 & 0,53 & 0,03 & 0,25 \\
\hline PA09 & 0,09 & 0,40 & 0,01 & 0,12 \\
\hline PA10 & 0,05 & 0,40 & 0,00 & 0,05 \\
\hline PA11 & 0,04 & 0,32 & 0,00 & 0,04 \\
\hline PA12 & 0,04 & 0,40 & 0,01 & 0,13 \\
\hline PA13 & 0,01 & 0,20 & 0,00 & 0,09 \\
\hline PA14 & 0,02 & 0,17 & 0,00 & 0,02 \\
\hline
\end{tabular}


em torno de $0,35 \mathrm{~m} . \mathrm{s}^{-1}$, sendo cerca de 7 vezes mais intensas do que as correntes do interior da Enseada das Palmas $\left(0,05 \mathrm{~m} \cdot \mathrm{s}^{-1}\right)$.

A Figura 11 mostra a dispersão de enterococos associada à passagem de um sistema frontal, com fluxo predominante na direção NE, devido a ventos de SE, às 13:00h (GMT) do dia 05/02/2009. Nota-se que não há grande transporte de poluentes para fora da área da Enseada das Palmas, devido à proteção natural que o local recebe da geomorfologia da ilha contra a influência direta das correntes provenientes de sul e sudoeste.

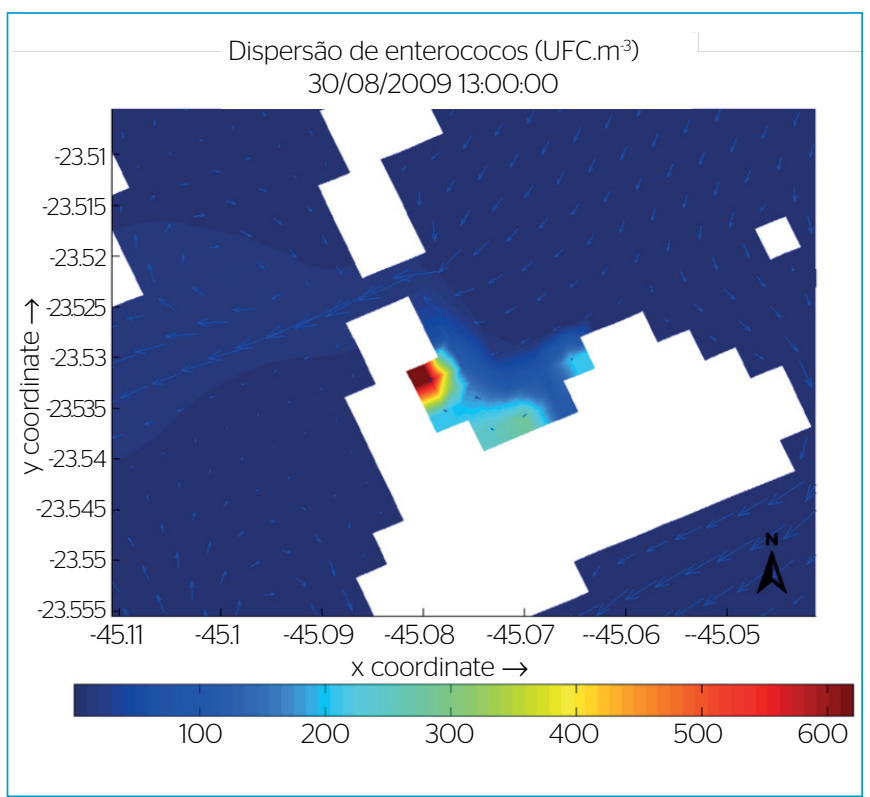

Figura 9 - Dispersão de enterococos (em UFC. $\mathrm{m}^{-3}$ ) e direção das correntes na região da Enseada das Palmas, às 13:00h (GMT) do dia 30/08/2009.

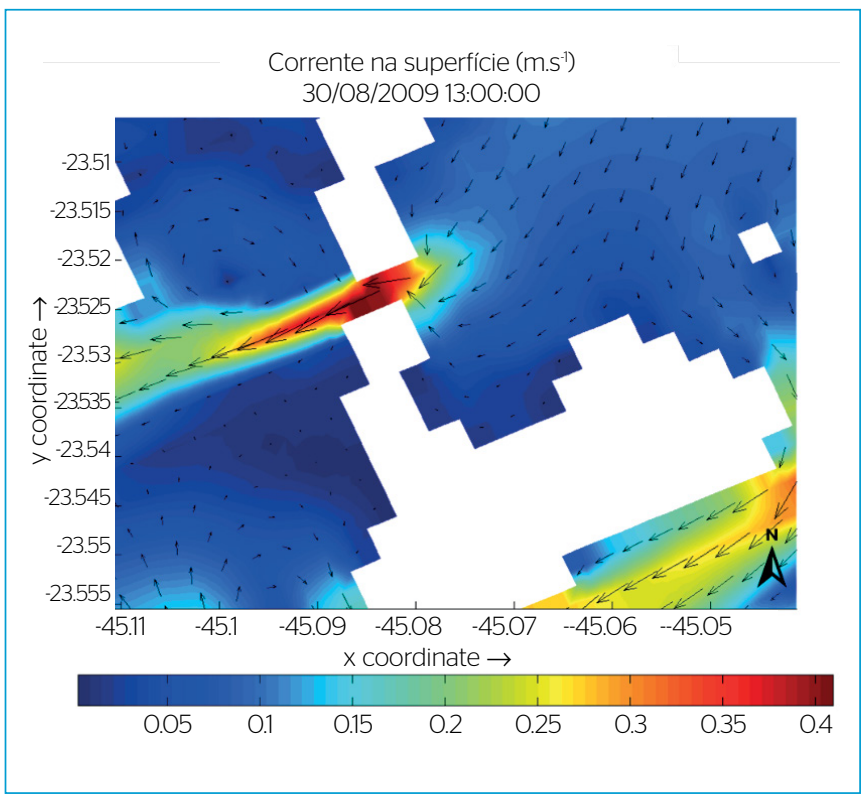

Figura 10 - Direção e intensidade das correntes (em ${\left.\mathrm{m} . \mathrm{s}^{-1}\right)}$ ) na região da Enseada das Palmas, às 13:00h (GMT) do dia 30/08/2009.

\section{CONCLUSÕES}

As águas nas enseadas do Flamengo e das Palmas, com relação aos parâmetros microbiológicos, mantiveram condições adequadas de balneabilidade ao longo dos meses de simulação (ver concentrações calculadas pelo modelo nas Tabelas 3 e 4, para as posições da Figura 2). Entretanto, a presença de valores mais altos de bactérias em fevereiro sugere maior cuidado na utilização dessas águas por banhistas na alta temporada. Os afluentes que deságuam nesses locais recebem fontes não pontuais de contaminação, como as águas de drenagem continental, que acarretam aumento na densidade de microrganismos na água do mar, inclusive os patogênicos, principalmente nos meses de verão, devido ao aumento das chuvas, à alta concentração de pessoas nas praias e ao aumento nos despejos de esgoto e lixo. Outras fontes difusas de contaminação podem estar presentes nas praias, como a areia (SHIBATA et al., 2004; WRIGHT et al., 2011).

A análise dos resultados do modelo, considerando as forçantes de maré, ventos e densidade, permite afirmar que o sistema de correntes das enseadas, determinado pela geomorfologia da região, não confere uma alta capacidade de diluição e dispersão de efluentes (ver Figuras 5 a 11). No Saco da Ribeira, por exemplo, notou-se que a baixa dispersão pode manter maiores concentrações de poluentes próximo à Praia do Perequê-Mirim (ponto FL03). A baixa capacidade de dispersão pode ocasionar a presença de poluentes em concentrações acima dos níveis naturais, causando contaminação e poluição no meio em questão, o que resulta em efeitos biológicos adversos e em risco à saúde dos banhistas.

É possível deduzir que a menor taxa de renovação das águas das enseadas contribui para a concentração dos poluentes, limitando, assim, a capacidade de diluição do meio receptor. Todavia, a circulação marinha

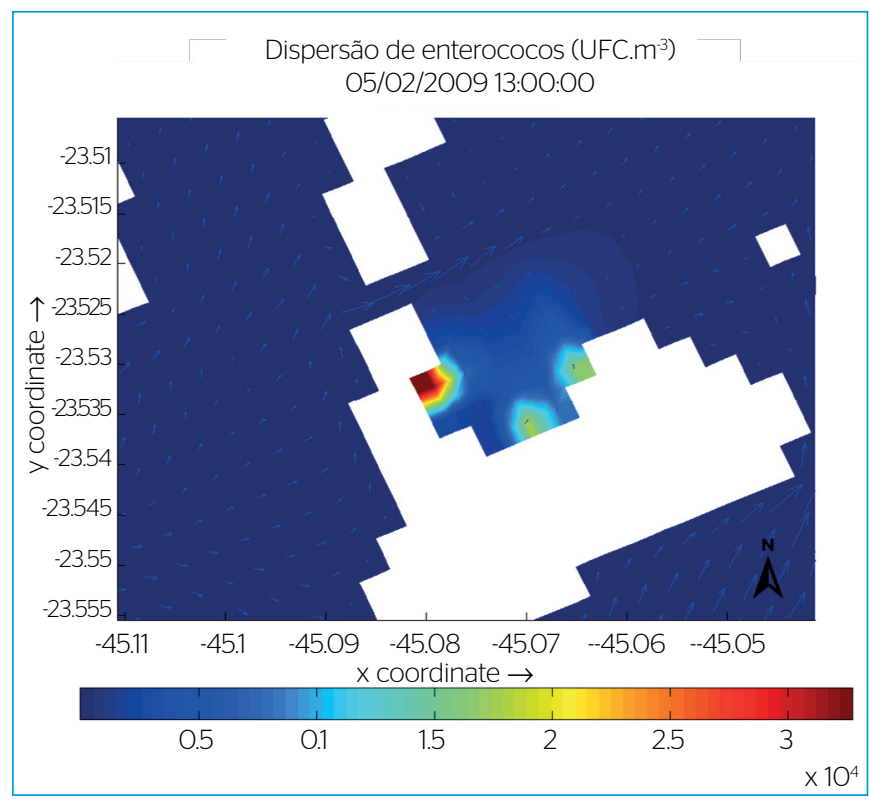

Figura 11 - Dispersão de enterococos (em UFC. $\mathrm{m}^{-3}$ ) e direção das correntes na região da Enseada das Palmas, às 13:00h (GMT) do dia 05/02/2009. 
(apesar de reduzida) e os processos envolvidos no decaimento das bactérias associados a fatores naturais (salinidade, temperatura e radiação solar) se mostraram suficientes para a difusão dos poluentes nas enseadas e para a diminuição de suas concentrações (sobretudo a radiação solar).

A modelagem ambiental reproduziu de maneira satisfatória os processos envolvidos no transporte e na difusão de parâmetros microbiológicos, contribuindo para o conhecimento dos efeitos das atividades humanas no sistema costeiro de Ubatuba. A análise da qualidade das águas destinadas à recreação, além de ser uma ação importante em termos de saúde pública, também se justifica em vista da importância da atividade turística na região de estudo e de sua grande relevância para o planejamento ambiental.

\section{REFERÊNCIAS}

ABSHER, T.M. Aspectos Oceanográficos e Malacofauna Bêntica da Enseada das Palmas - Ilha Anchieta (São Paulo). (1982). 109 f. Tese (Doutorado). Instituto Oceanográfico, São Paulo.

BELKIN, S.; COLWELL, R.R. (2006) Oceans and health: pathogens in the marine environment. Springer, v.1, p. 69-92.

BOEHM, A.B.; SASSOUBRE, L.M. (2014) Enterococci as Indicators of Environmental Fecal Contamination. In: GILMORE, M. S.; CLEWELL, D. B.; IKE, Y.; SHANKAR, N. (Eds.) Enterococci: From Commensals to Leading Causes of Drug Resistant Infection, Boston: Massachusetts Eye and Ear Infirmary. Disponível em: <http://www.ncbi.nlm.nih. gov/books/NBK190421>. Acesso em: 28 nov. 2015.

BRUM, R.S.; NEVES, C.S.; KIRINUS, E.P.; SANTOS, R; EMMENDORFER, L.R. (2011) Modelagem ambiental: perspectivas e contribuições. Revista Jr de Iniciação Científica em Ciências Exatas e Engenharia, v. 3, p. 15-20.

CAMARGO, R.; HARARI, J. (2014) Tides and Wind-driven Circulation in the Tropical and Southern Atlantic Ocean: The BRAZCOAST System. Atmospheric and Oceanic Science Letters, v. 7, p. 476-480.

CASTRO, B.M. (1996) Correntes e massas de água da plataforma continental norte de São Paulo. 248 f. Tese (Livre Docência) Instituto Oceanográfico, Universidade de São Paulo, São Paulo.

CETESB. Companhia Ambiental do Estado de São Paulo. (2005) Relatório de Qualidade das Águas Litorâneas no Estado de São Paulo - Balneabilidade das Praias - 2004. São Paulo: CETESB.

CETESB. Companhia Ambiental do Estado de São Paulo. (2009) Relatório de Qualidade das Praias Litorâneas no Estado de São Paulo. São Paulo: CETESB. (Série Relatórios)

CETESB. Companhia Ambiental do Estado de São Paulo. (2014) Relatório de Qualidade das Praias Litorâneas no Estado de São Paulo - 2013. São Paulo: CETESB. (Série Relatórios)

CETESB. Companhia Ambiental do Estado de São Paulo. (2015) Relatório de Qualidade das Águas Salinas e Salobras no Estado de São Paulo 2014. São Paulo: CETESB. (Série Relatórios)

CHENG, R.T.; BURAU, J.R.; GARTNER, JW. (1991) Interfacing data analysis and numerical modeling for tidal hydrodynamic phenomena. In: PARKER, B.B. (Ed.), J. Wiley and Sons, Tidal hydrodynamics, p. 201-219.
DELTARES. (2014a). Delft3D. Functional Specifications. User Manual, Deltares, Delft, The Netherlands, 48p.

DELTARES. (2014b). Delft3D-FLOW. Simulation of multi-dimensional hydrodynamics flows and transport phenomena, including sediments. User Manual, Deltares, Delft, The Netherlands, 652p.

DELTARES. (2014c). D-Water Quality. Versatile water quality modeling in 1D, 2D or 3D systems including physical, (bio) chemical and biological processes. User Manual, Deltares, Delft, The Netherlands, 394p.

FERREIRA, F.R. (2015) Análise da qualidade ambiental das praias do Guarujá (SP) através da avaliação de lançamentos pontuais de esgotos - Emissário Submarino do Guarujá, canais artificiais e rios da Praia do Perequê. 135 f. Dissertação (Mestrado) - Instituto de Energia e Ambiente da Universidade de São Paulo, São Paulo.

GARCIA, G.E.; GONÇALVES, J.E. (2O11) Implementação de Modelo Numérico para Avaliação do Transporte de Sedimentos no Reservatório de Itaipu - PR. Revista Brasileira de Recursos Hídricos, v. 16, n.3, p. 49-58.

JUNG, A.; CANN, P.L.; ROIG, B.; THOMAS, O.; BAURES, E.; THOMAS, M. (2014) Microbial Contamination Detection in Water Resources: Interest of Current Optical Methods, Trends and Needs in the Context of Climate Change. International Journal of Environmental Research and Public Health, v. 11, p. 4292-4310.

JIAN, L.; ZHONGWU, J.; WENJUN, Y. (2014) Numerical modeling of the Xiangxi River algal bloom and sediment-related process in China. Ecological Informatics, v. 22, p. 23-35.

LANÇONE, R.B.; DULEBA, W.; MAHIQUES, M.M. de. (2005) Dinâmica de fundo da Enseada do Flamengo, Ubatuba, Brasil, inferida a partir da distribuição espacial, morfometria e tafonomia de foraminíferos. Revista Brasileira de Paleontologia, v. 8, n. 3, p. 181-192.

LUIJENDIJK, A. (2001) Validation, calibration and evaluation of a Delft3D-FLOW model with ferry measurements. 92 f. Dissertação (Mestrado) - Delft Hydraulics University, Delft.

MAHIQUES, M.M. (1992) Variações temporais na sedimentação holocênica dos embaiamentos da região de Ubatuba (SP). 352p. Tese (Doutorado) - Instituto Oceanográfico, Universidade de São Paulo, São Paulo. 
MAHIQUES, M.M. (1995) Dinâmica sedimentar atual nas enseadas da região de Ubatuba, Estado de São Paulo. Boletim do Instituto Oceanográfico, São Paulo, v. 43, n. 2, p. 101-110.

MAHIQUES, M.M.; TESSLER, M.G; FURTADO, V.V. (1998) Characterization of energy in enclosed bays of Ubatuba region, south-eastern Brazil. Estuarine, Coastal and Shelf Science, v. 47, p 43-44.

MANCINI, J.L. (1978) Numerical estimates of coliform mortality rates under various conditions. Journal Water Pollution Control Federation, p. 2477-2484.

MANTELATTO, F.L.; FARIA, F.C.R.; BIAGI, R.; MELO, G.A.S. (2004) Majoid crabs community (Crustacea: Decapoda) from infralittoral rocky/sandy bottom of Anchieta Island, Ubatuba. Brazilian Archives of Biology and Technology, p. 273-279.

McBRIDE, G.B.; STOTT, R.; MILLER, W.; BAMBIC, D.; WUERTZ, S. (2O13) Discharge-based QMRA for estimation of public health risks from exposure to stormwater-borne pathogens in recreational waters in the United States. Water Research, v. 47, p. 5282-5297.

MENDONÇA, A.S.F. (2001) Desenvolvimento de sistema de suporte à decisão para subsídio à outorga de uso de água de rios, lagos e reservatórios considerando fontes pontuais e difusas. In: Edital CTHIDRO 01/2001.

NEVES, R. (2007) Numerical models as decision support tools in coastal areas. Assessment of the Fate and Effects of Toxic Agents on Water Resources, NATO Security through Science Series, 171-195.

PEREIRA, R.S.; NIENCHESKI, L.F.H. (2004) Avaliação da qualidade da água da Lagoa dos patos a partir de um modelo matemático. In: I Seminário e Workshop em Engenharia Oceânica. 2004, Rio Grande. Anais... Rio Grande. FURG.

PICKERING, A.J.; JULIAN, T.R.; MAMUYA, S.; BOEHM, A.B.; DAVIS, J. (2011) Hand fecal contamination among Tanzanian mothers varies temporally and following household activities. Tropical Medicine \& International Health, v. 16, n.2, p. 23-239.
SALIBA, L.J.; HELMER, R. (1990) Health risks associated with pollution of coastal bathing Waters. World Health Statistics Quarterly, v. 43, p. 177-184.

SÃO PAULO (Estado). Secretaria do Meio Ambiente. Coordenadoria de Planejamento Ambiental Estratégico e Educação Ambiental. (2005) Zoneamento Ecológico-Econômico do Litoral Norte. São Paulo, 56p.

SÃO PAULO (Estado). Secretaria do Meio Ambiente. Coordenadoria de Planejamento Ambiental. (2011) Meio Ambiente Paulista: Relatório de Qualidade Ambiental 2011. São Paulo, 256p.

SEADE - FUNDAÇÃO SISTEMA ESTADUAL DE ANÁLISE DE DADOS. Disponível em: <http://www.seade.gov.br>. Acesso em: 10 jan. 2016.

SHIBATA, T:; SOLO-GRABRIELE, H.M.; FLEMING, L.E.; ELMIR, S. (2004) Monitoring marine recreational water quality using multiple microbial indicators in an urban tropical environment. Water Research, v. 38, p. 3119-3131.

SOLLER, J.; SCHOEN, M.E.; VARGHESE, A.; ICHIDA, A.M.; BOEHM, A.B.; EFTIM, S.; ASHBOLT, N.J; RAVENSCROFT, J.E. (2O14) Human health risk implications of multiple sources of faecal indicator bacteria in a recreational waterbody. Water Research, v. 66, p.254-264.

WHO. World Health Organization. (2006) Guidelines for Safe Recreation-water Environments: Swimming Pool and similar Environments. Geneva: [s.n], v. 2, ISBN 9241546808.

WILLMOTT, C.J. (1981) On the validation of models. Physical Geography, v. 2, p. 184-194.

WRIGHT, M.E.; SOLO-GRABRIELE, H.M.; ABDELZAHER, A.M.; ELMIR, S.; FLEMING, L.E. (2011) The inter-tidal zone is the geographic location of elevated concentrations of enterococci. Water Science and Technology, v. 63, n. 3, p. 542-549.

ZHU, X.; WANG, J.D.; SOLO-GABRIELE, H.M.; FLEMING, L.E.; ELMIR, S. (2011) A microbial water quality model for recreational marine beaches. Water Research, v. 45, p. 2985-2995. 